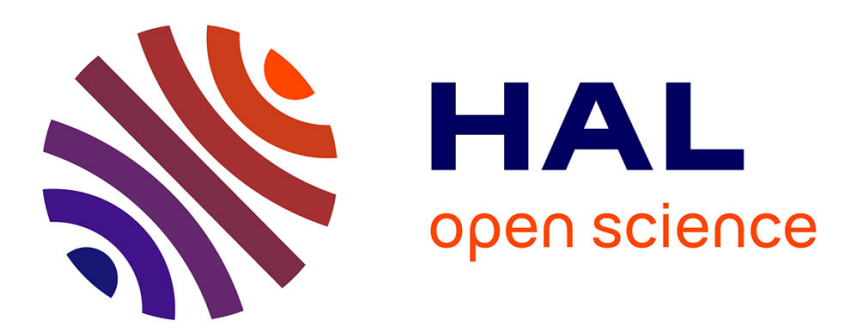

\title{
Obtaining polarized liquid helium 3 from optically oriented gas
}

\author{
G. Tastevin, P.J. Nacher, L. Wiesenfeld, M. Leduc, F. Laloë
}

\section{To cite this version:}

G. Tastevin, P.J. Nacher, L. Wiesenfeld, M. Leduc, F. Laloë. Obtaining polarized liquid helium 3 from optically oriented gas. Journal de Physique, 1988, 49 (1), pp.1-6. 10.1051/jphys:019880049010100 . jpa-00210670

\section{HAL Id: jpa-00210670 https://hal.science/jpa-00210670}

Submitted on 1 Jan 1988

HAL is a multi-disciplinary open access archive for the deposit and dissemination of scientific research documents, whether they are published or not. The documents may come from teaching and research institutions in France or abroad, or from public or private research centers.
L'archive ouverte pluridisciplinaire HAL, est destinée au dépôt et à la diffusion de documents scientifiques de niveau recherche, publiés ou non, émanant des établissements d'enseignement et de recherche français ou étrangers, des laboratoires publics ou privés. 


\title{
LE JOURNAL DE PHYSIQUE
}

Classification

Physics Abstracts

$32.80 \mathrm{~B}-67.50$

\section{Obtaining polarized liquid helium 3 from optically oriented gas}

\author{
G. Tastevin, P.J. Nacher, L. Wiesenfeld*, M. Leduc and F. Laloë \\ Laboratoire de Physique de l'E.N.S, 24 rue Lhomond, 75005 Paris, France
}

(Reçu le 19 octobre 1987, accepté le 3 novembre 1987)

\begin{abstract}
Résumé.- Il est possible de produire de l'hélium trois liquide polarisé par liquéfaction d'un gaz préalablement orienté par pompage optique. Nous avons de cette façon obtenu des polarisations nucléaires de plus de $40 \%$ dans un liquide à $\simeq 400 \mathrm{mK}$ et pression presque nulle. Le temps de relaxation nucléaire est de quelques minutes, comparable au temps de relaxation en volume dans le liquide. Les signaux de RMN que donne le liquide sont fortement déplacés en fréquence, ce qui fournit une façon précise et commode de mesurer la polarisation nucléaire, et également de suivre le mouvement de liquide qui coule le long des parois de la cellule.
\end{abstract}

\begin{abstract}
Spin polarized liquid helium three can be obtained by liquefaction of a gas polarized by laser optical pumping. We show that this method can lead to nuclear polarizations exceeding $40 \%$ in a liquid at about $400 \mathrm{mK}$ and almost zero pressure. The relaxation time of the orientation is a few minutes, comparable to the relaxation time of weakly polarized bulk liquid. The NMR signals given by the liquid are strongly shifted in frequency ; this provides a precise and convenient way to measure the polarization and to follow the motion of the liquid inside the experimental cell.
\end{abstract}

\section{Introduction.}

Optical pumping in gaseous helium three [1], when a laser is used as a pumping source, can provide nuclear polarizations exceeding $60 \%$ [2]. The method can be used to observe various physical effects including modifications of the importance of the role played by particle indistinguishability in the transport properties of the gas. In this way, heat conduction changes introduced by quantum statistics have recently been observed [3]. Moreover, a strong nuclear polarization can also affect equilibrium properties of

* Permanent address : CNRS, SNCI, BP $166 \mathrm{X}$, F-38042 Grenoble Cedex, France. the system, for example liquid gas transition diagrams $[4,5]$. Studying this class of effects requires the obtention of a strongly polarized helium three liquid, with a well controlled, homogeneous, nuclear polarization at the interface. The aim of the present article is to show that this is possible by fast liquefaction of an optically pumped helium gas.

Similar experiments have already been performed by Mc Adams and Walters [6] at a time when no laser was available for this purpose. In addition to laser optical pumping, we have made a systematic use of "cryogenic coatings" : solid hydrogen [7] or liquid helium four [8] is deposited on the walls in order to reduce the nuclear relaxation at low temperatures. These two improvements probably explain why we have ob- 
tained nuclear polarizations which are two orders of magnitude larger than in [6]. Another difference is that our experimental set up includes a helium three refrigerator which gives access to lower temperatures.

Other methods are available to obtain highly polarized liquid helium three. The "Castaing-Nozières" fast melting technique has been used by several groups [9-14] to produce samples of polarized liquid and study their properties. We briefly discuss at the end of this letter how the two methods compare. Another way of obtaining polarized helium three liquid is the use of surface effects on small fluorocarbon particles, as shown in references [15-17], but this method has not yet provided high nuclear polarizations.

\section{Experimental set up.}

Figure 1 shows the experimental set up, where the sample of helium three under study is confined inside a long vertical glass container made of three cells connected by a long $(\simeq 80$ $\mathrm{cm}$ ) tube [18] : cell $\mathrm{A}$, at room temperature, cell $\mathrm{B}$ at $\simeq 4 \mathrm{~K}$ and cell $\mathrm{C}$ which is inside the helium three cryostat and can be cooled down to about $400 \mathrm{mK}$. The whole system is surrounded by a set of 5 big coils (not shown in the figure) which create a homogeneous vertical magnetic field of approximately 13 Gauss. This value is not critical, since optical pumping does not require any magnetic field to operate, but it is convenient to have a "holding magnetic field" in order to avoid too much sensitivity of the nuclear spins to any stray magnetic field created by the environment. What is more critical is the homogeneity of the magnetic field : the random thermal motion of atoms in field gradients introduces a relaxation process $[19,20]$ which may destroy the nuclear polarization if too fast. The 5 magnetic coils were designed to provide a relative homogeneity better than $10^{-4}$ over $\simeq 1$ meter along their axis. In addition, the cryostat was exclusively made of materials carefully chosen for amagnetism, mostly pyrex glass or-only at distances more than $20 \mathrm{~cm}$ from the lower cell- stainless steel. A more detailed description of the experiment and its characteristics can be found in references [21] and [22].

The nuclear polarization is initially created in cell $\mathrm{A}$ by optical pumping [1]. The light source is a LNA laser which delivers about $300 \mathrm{~mW}$ of

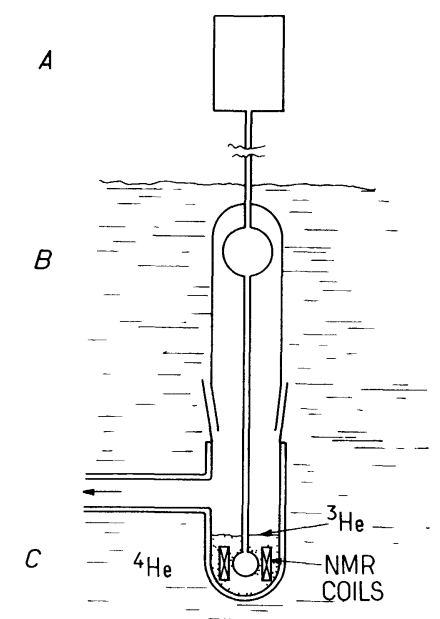

Fig.1.- Sketch of the experimental set-up. The container of the helium three sample is made of three different cells, connected by a long tube : the upper cell $A$ at room temperature, where the nuclear polarization is obtained by laser optical pumping ; the intermediate cell B at $\simeq 4 \mathrm{~K}$ which acts as a polarized gas reservoir ; the lowest cell $\mathrm{C}$ which is immersed in the cryogenic helium three bath at variable temperature and surrounded by the NMR pick-up coils.

cw power at the helium wavelength [23]. The transfer of nuclear polarization to the lowest cell (cell $\mathrm{C}$ ) is ensured by diffusion of the atoms along the long connecting tube [18]. The role of cell B, which is inserted about $15 \mathrm{~cm}$ above cell $\mathrm{C}$, is to store polarized helium three gas at about 4 Kelvin. The whole container (i.e. the three cells connected by the tube) was made of pyrex glass and carefully evacuated and cleaned before filling with a mixture of helium three (pressure $\simeq 3$ torr) and hydrogen ( $\simeq 1.5$ torr). When cells $B$ and $\mathrm{C}$ are cooled down to a few Kelvin, a coating of a few layers of solid hydrogen forms on the cold inner walls of the container ; this gives long relaxation times (of the order of 1 hour above 1 or 2 Kelvin), instead of the very short relaxation times that would be obtained on cold bare pyrex walls [7]. When the temperature gradient along the tube is well controlled [18], an efficient transfer of polarization (sometimes almost complete) is obtained.

The magnetization of cell $\mathrm{C}$ is monitored by NMR techniques. Resonant RF pulses (at $42 \mathrm{kHz}$ ) are applied to the induction coils ; they create a small transverse nuclear polarization which, during its precession, is the source of a FID signal collected in a pair of tuned pick up 
coils. The corresponding voltage is analysed by a lock-in amplifier and stored by a microcomputer, which can perform Fourier transform .

\section{Experimental procedure.}

The preparation of polarized liquid helium three is done in two steps. First, about $3 \mathrm{~cm}^{3}$ of cryogenic liquid helium three is accumulated around the lower cell at about 1.5 Kelvin. Most atoms inside the container then sit in bulb B at $\simeq 4$ Kelvin. After about one hour of laser optical pumping in the upper cell, an equilibrium is almost reached and the nuclear polarization in cell $\mathrm{B}$ is 80 or $90 \%$ of that in cell A. Typically the polarization is $55 \%$ in cell $A$ and 45 to $50 \%$ in cell $B$. The second step is done by pumping rapidly on the helium three cryogenic bath, so that the temperature of cell C decreases to about $400 \mathrm{mK}$ in less than one minute : under these conditions, the liquefaction temperature of the helium gas in the container is reached and more than $2 / 3$ of the gas condense on the coldest part of the walls (i.e. near the surface of the pumped helium three cryogenic bath). This process forms on the wall a film of liquid helium three of total volume approximately half a cubic millimeter; it probably condenses on an area of the order of one square centimeter, and has a thickness of the order of twenty to thirty microns. The polarized sample then flows along the walls down to the lowest part of cell C. Small, almost non destructive, tilting NMR pulses allow one to monitor the polarization of the sample during all these processes. After nuclear relaxation has destroyed the nuclear polarization of the sample, the temperature of the helium three cryogenic bath is raised to 1.5 Kelvin and a new experiment can be done.

\section{Results.}

Before liquefaction the observed spectrum of the FID signal consists in a single narrow peak at the Larmor frequency in the applied field. Figure 2 shows the spectrum after liquefaction : the central peak, at the same frequency as before liquefaction, is due to the atoms remaining in the gas phase. The two shifted peaks correspond to the polarized liquid formed on the walls of cell C. The origin of the shifts is nothing but the strong demagnetizing field created by the liquid itself. In most NMR experiments with liquid helium three, such shifts are too small to be ob- served but, here, with our highly polarized samples, they are very large, as in very recent experiments on highly polarized solid helium three [24]. An order of magnitude of the size of the shifts can be estimated by noticing that a spherical sample of liquid helium three with a $50 \%$ nuclear polarization creates in its close neighbourhood a field of approximately 1 Gauss, corresponding to a frequency shift of $3 \mathrm{kHz}$. In addition to high polarization, there is another reason why the NMR shifts are especially easy to observe in this experiment: in general, for samples with any shape, the demagnetizing field has strong spatial variations over the sample, so that the observed spectrum consists in a broadened line rather than in narrow shifted lines. This is not the case here, because our liquid samples are thin helium films with a quasi two dimensional shape. Under these circumstances, the local field experienced by an atom inside the film is influenced only by the other atoms that are situated at a distance not much larger than the film thickness; moreover, it depends only on the orientation of the wall with respect to the external static magnetic field $\mathbf{B}_{0}$. Similar situations were observed recently in experiments on spin polarized hydrogen [25]. One can show $[25,21]$ that, if $\theta$ is the angle between $B_{0}$ and the normal to the wall, the frequency shift is given by :

$$
\Delta \omega=\mu_{0} \mu_{n} \gamma M\left(3 \cos ^{2} \theta-1\right) / 2
$$

where $\mu_{n}$ is the magnetic moment of a helium three nucleus, $\gamma$ the gyromagnetic ratio, and $M$ a dimensionless number $(-1 \leq M \leq 1)$ which characterizes the polarization of the sample $(M$ has the same sign as the angular momentum and therefore the sign opposite to that of the magnetic moment). If $M$ is positive, for a vertical wall $(\theta=\pi / 2)$ the shift is approximately $+36 \mathrm{~Hz}$ per percent (of $M$ ); for a horizontal wall $(\theta=0)$, $-72 \mathrm{~Hz}$ per percent.

This explains why two additional NMR peaks occur in figure 2 : one is positively shifted and corresponds to the helium three liquid that is condensed on the vertical walls of the cell, which turns out to be the coldest point in this particular experiment. After a few seconds, because the liquid flows towards the bottom of the cell where the wall is horizontal, the weight of this line decreases in favour of a second NMR line which appears with twice the opposite shift. Simultaneously, the two shifts decrease in time because 
they are proportional to $M$ which relaxes towards zero. After about one or two minutes, the effects of the nuclear relaxation begin to take over and the weights as well as the shifts of both NMR peaks decay to zero.

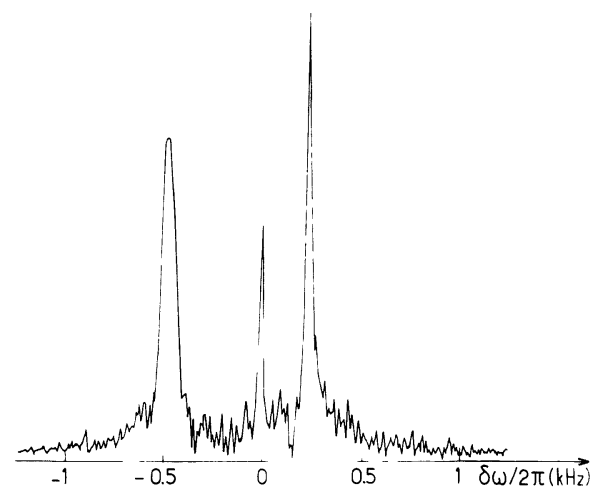

Fig.2.- Fourier transform of a FID signal. The central line corresponds to the atoms in the gas phase, the upshifted line to atoms in a liquid film deposited on vertical walls, the downshifted line to atoms in the puddle of liquid which has flowed to the horizontal bottom of the cell.

Measuring the shifts as a function of time is an easy and accurate way to measure the nuclear polarization of the liquid film, as well as its relaxation time : this method eliminates the need for any other calibration than frequency calibration ; it can readily be applied for example to the sample of liquid on vertical walls, although the number of atoms is constantly varying in time.

The experiment of figure 2 was done with a spherical lowest cell $\mathrm{C}$, and the polarized liquid was condensed on the walls of the connecting tube, about one centimeter above the top of sphere C. With this geometry, we were not able to obtain more than $20 \%$ for the polarization of the liquid sample. Another geometry was tried, with no sphere $\mathrm{C}$ but only a conical ending of the tube ; then the NMR spectrum shows a narrow, well defined, line arising from the film formed on the vertical walls of the tube, and a broad structure due to the liquid which has flowed down to the conical bottom of the container. This broad structure instead of a narrow line could be expected for a sample which is no longer a thin film but rather three dimensional. The initial polarization of the liquid could be obtained from the shift of the narrow line : polarizations beyond $40 \%$ were consistently obtained, and a maxi- mum polarization of $44 \%$ was measured several times.

Figure 3 shows a plot of the shift as a function of time in semi-logarithmic scale. The time decay of the polarization does not depart significantly from an exponential ; this shows that the longitudinal relaxation probability is not a rapid function of $M$ at this temperature, where the degeneracy of the liquid is only weak. The corresponding lifetime is $\simeq 4 \mathrm{~min}$, comparable to longitudinal relaxation time in bulk liquid $[26,27]$.

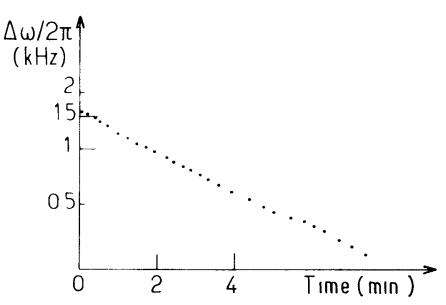

Fig.3. - Time evolution of the frequency shift in the vertical liquid film, shown with semilog scale; the shift is directly proportional to the nuclear polarization $(1 \mathrm{kHz}$ corresponds to $M \simeq 30 \%$ ). Its almost exponential decay indicates that, for this nondegenerate liquid sample, the longitudinal relaxation rate does not depend strongly on the nuclear polarization.

\section{Conclusion.}

In conclusion, optical pumping can indeed be used as a tool for the study of the properties of liquid spin polarized helium three, in conditions where relaxation times are not significantly shorter than in bulk liquid. The observed NMR shifts provide a direct way for measuring the sample polarization and for observing its motion along the wall covered by solid hydrogen. The fact that the lines are narrow indicates that the shape of the sample is close to a thin film, in other words that liquid helium three wets the solid hydrogen coating in our experimental conditions. Measurements of the viscosity of the flowing film could probably be done rather directly from the information obtained on the motion of the film. No $M$ dependence of the longitudinal relaxation has been observed so far.

In its present form, the experiment can be improved in several ways. Particularly attractive would be its extension to lower temperatures ; this would require the use of a dilution refrigera- 
tor but at the same time open up the possibility of creating degenerate spin polarized liquid and of studying its equilibrium or transport physical properties. Since the intrinsic relaxation rate of bulk liquid helium three decreases when the temperature decreases (at least for weakly polarized samples), one may hope to observe longer lifetimes for the nuclear polarization. The present method is complementary of the "Castaing-Nozières" fast melting method [9], which provides spin polarized liquid helium three with nuclear polarizations comparable to ours, but at a higher pressure. In comparison, our technique provides much smaller samples (fraction of a cubic millimeter), because of intrinsic limitations which have their source in the intensity of the pumping laser and the nuclear relaxation [4] ; on the other hand, optical pumping samples have probably a homogeneous nuclear polarization, which is not always the case in the fast melting method ; moreover, liquefying spin polarized gas might be a more appropriate method than fusing solid if one is interested in the study of the liquid-gas equilibrium curves. Another interesting extension of this experiment would be to condense the polarized gas into superfluid liquid helium four ; this would lead to experiments on polarized dilute solutions of helium three in helium four by a different method than polarization in high magnetic fields $[28,29]$.

The authors express their gratitude to J. Brossel whose help during the experiment played an essential role. They also wish to thank $M$. Chapellier and B. Hebral for very useful advice for the design of the cryostat. This work was done in the Laboratoire de Spectroscopie Hertzienne de l'ENS, which is laboratoire associé au CNRS, $n^{\circ} 18$.

\section{References}

[1] Colegrove, F.D., Schearer, L.D., and Walters, G.K., Phys. Rev. 132 (1963) 2561.

[2] Nacher, P.J., Leduc, M., Trénec, G., and LALOE, F., J. Phys. Lett. France 43 (1982) L-525.

[3] Leduc, M., Nacher, P.J., BetTs, D.S., Daniels, J.M., TAstevin, G., and Laloe, F., Europhys. Lett. 4 (1987) 59.

[4] Lhuillier, C., and Laloe, F., J. Phys. France 40 (1979) 239.

[5] Stringari, S., Barranco, M., Polls, A., NACher, P.J., and LAloE F., J. Phys. France 48 (1987).

[6] MCAdams, H.H., and Walters, G.K., Phys. Rev. Lett. 18 (1967), 436.

McAdams, H.H., Phys. Rev. 170 (1968) 276.

[7] LeFÈbVRE-SEguiN, V., NACHER, P.J., BROSSEL, J., HARDY, W.N., and LALOE, F., J. Phys. France 46 (1985) 1145.

[8] Himbert, M., Lefìvre-Seguin, V., NACHER, P.J., DUPONT-Roc, J., LEDUC, M., and LALOE, F., J. Phys. Lett. France 44 (1983) L-523.

[9] Castaing, B., and Nozières, P., J. Phys. France 40 (1979) 257.
[10] Schumacher, G., Thoulouze, D., CasTaING, B., Chabre, Y., Segransan, P., and Joffrin, J., J. Phys. Lett. 40 (1979) 143.

[11] Chapellier, M., Frossati, G., and RASMUSSEN, F.B., Phys. Rev. Lett. 42 (1979) 904.

[12] Kopietz, P., Dutta, A., and ARchie, C.N., Phys. Rev. Leti. 57 (1986) 1231.

[13] Frossati, G., Bedell, K.S., WiEgers, S.A.J., and Vermeulen, G.A., Phys. Rev. Lett. 57 (1986) 1032.

[14] Bonfait, G., Puech, L., Halperin, W.P., and Castaing, B., Europhys. Lett. 3 (1987) 489.

[15] Friedmann, L.J., Millet, P.J., and RICHARDSON, R.C., Phys. Rev. Lett. $\mathbf{4 7}$ (1981) 1078.

HAMMEL, P.C., RouKes, M.L., HU, Y., Gramila, T.J., MamiYa, T., and RICHARDSON, R.C., Phys. Rev. Lett. 51 (1983) 2124.

[16] Chapellier, M., J. Phys. Lett. 43 (1982) L-609.

[17] Schuhl, A., Maegawa, S., Meisel, M.W., and Chapellier, M., Phys. Rev. Lett. 54 (1985) 1952. 
[18] Leduc, M., Crampton, S.B., Nacher, P.J., and LALOE, F., Nucl. Sci. Appl. 2 (1984) 1.

[19] ScheareR, L.D., and Walters, G.K., Phys. Rev. 139A (1965) 1398.

[20] BARBÉ, R., Leduc, M., and Laloe, F., $J$. Phys. France 35 (1974) 699 and 935.

LEFÈVRE-SEguiN, V., NACHER, P.J., and Laloe, F., J. Phys. France 43 (1982) 737.

[21] Tastevin, G., Thèse, Paris (1987).

[22] NACher, P.J., TASTEVIN, G., and WiesenFELD, L., submitted to Rev. Sci. Instr.

[23] Daniels, J., Schearer, L.D., Leduc, M., and NACHER, P.J., J. Opt. Soc. Am. B 4 (1987) 1133

[24] OsherofF, D.D., and Cross, M.C., Phys.
Rev. Lett. 59 (1987) 94.

[25] REYNoldS, M.W., SHINKoda, I., HARDy, W.N., and BERLINSKY, A.J., Phys. Rev. $B$ 31 (1985) 7503 .

[26] Godfrin, H., Frossati, G., Hebral, B., and Thoulouze, D., J. Phys. Colloq. France 41 (1980) C7-275 and references therein.

[27] Vollhardt, D., and Wölfe, P., Phys. Rev. Lett. 17 (1981) 190.

[28] Gully, W.J., and MulliN, W.J., Phys. Rev. Lett. 52 (1984) 1810.

[29] Owers-Bradley, J.R., Chocolacs, H., Mueller, R.M., Buchal, Ch., Kubota, M., and PoBell, F., Phys. Rev. Lett. 51 (1983) 2120. 